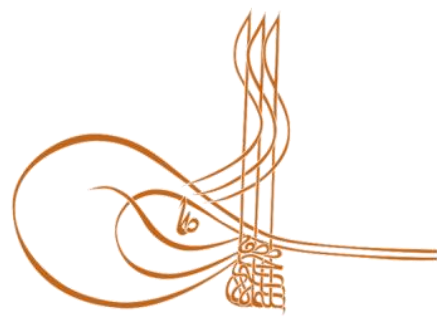

www.turkishstudies.net/economy
Turkish Studies - Economics, Finance, Politics

eISSN: $2667-5625$

Research Article / Araştırma Makalesi

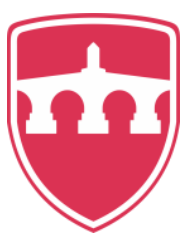

INTERNATIONAL BALKAN

UNIVERSITY

Sponsored by IBU

\title{
Mamül Maliyetlerinin Belirlenmesinde Etkili Olan Maliyet Sürücülerinin Faaliyet Tabanlı Maliyetleme Tekniğinde Ahp ile Tespiti: Bir Uygulama
}

\author{
Determining the Cost Drivers Playing Effective Role in Product Costs by Using Ahp Method in \\ Activity-Based Costing Method an Application
}

Öznur Arslan*

\begin{abstract}
Under the conditions of increasing competition, the companies tend to gradually decrease their costs. In order to decrease the costs, it is very important to accurately determine these costs. The objective of the present study is to integrate the Activity Based Costing (ABC) and Analytical Hierarchy Process (AHP) methods in order to ensure accurate distribution of costs, which accumulate on the cost drivers, to the activities and products. In order to achieve this objective, the drivers to be employed in distributing the costs were determined using the Analytical Hierarchy Process (AHP) and 7 different specialists performed analyses in order to determine the distribution keys. As a result of this study, it was found that the unit costs, which the company calculates using the traditional cost accounting method, and the unit costs calculated using ABCAHP method are different from each other. By using ABC-AHP method, differing from the unit costs that the company is currently using, it was determined that the activity processes and the activity costs that the companies used in calculating the costs at the product level are different. Among two types of model products that the company products, the unit cost was calculated to be 3\% higher for the wider folder (GK), whereas it was calculated to be $12 \%$ lower for the narrower folder (DK). This might cause significant changes in the financial tables depending on the sales volume of the company. Moreover, in the present study, which activity caused a higher level of cost was also found. Thus, the managers would be able to determine which activity created a higher level of cost.
\end{abstract}

Structured Abstract: The competition increased with the effects of globalization makes it difficult for companies to make a profit. The profit is the positive difference between income and expense. In cases of intense competition, it is very difficult and even impossible to increase the prices. Thus, the companies would choose to change the costs. Article 275 of Tax Procedure Law specifies the elements of product costs (commodity that is manufactured). The relevant provision is as follows.

"The cost of manufactured commodity (final or bulk products) contains following elements:

\footnotetext{
${ }^{*}$ Dr. Öğr. Üyesi, Sivas Cumhuriyet Üniversitesi, Cumhuriyet Meslek Yüksekokulu, Büro Hizmetleri ve Sekreterlik Bölümü Asst. Prof. Dr., Sivas Cumhuriyet University, Vocational School, Department of Office Services and Secretarial ORCID 0000-0001-5973-9107

oznurkul@cumhuriyet.edu.tr

Cite as/ Atıf: Arslan, Ö. (2020). Mamül maliyetlerinin belirlenmesinde etkili olan maliyet sürücülerinin faaliyet tabanlı maliyetleme tekniğinde ahp ile tespiti: bir uygulama, Turkish Studies - Economy, 15(1), 53-68. https://dx.doi.org/10.29228/TurkishStudies.40475

Received/Geliş: 08 January/Ocak 2020

Accepted/Kabul: 25 March/Mart 2020

Copyright $($ INTAC LTD, Turkey

Checked by plagiarism software

Published/Yayın: 30 March/Mart 2020

CC BY-NC 4.0
} 
1. Primary and raw material costs borne for manufacturing the product,

2. Labor cost per product,

3. Product's share in general production costs,

4. Product's share in general administrative costs (This share should be arbitrarily added to the product cost.),

5. Cost of packaging for the products, which must be sold in a package."

Taxpayers shall independently determine the cost of product, which they manufacture, as long as obeying the list given above. Accurate calculation of costs is a necessity for achieving the administrative efficacy. Although the costs of direct raw materials and supplies and the direct labor costs are loaded to the product cost in companies manufacturing multiple products, the allocation of general production costs causes significant problems. Since the Actual Indirect Costs (AIC) cannot be directly allocated to the products, the problem of "allocation key" arises. In allocating the costs to the activities, ABC and AHP were integrated and then applied to an industrial company based in Sivas province. The results obtained are a strategic decisionmaking factor for the companies. The allocation keys needed for applying $\mathrm{ABC}$ were obtained using AHP evaluations of 7 different specialists.

The companies face with many problems while allocating the general production costs in traditional costing method. Thus, the product costs cannot be achieved accurately. The contemporary costing methods are used in more accurately allocating the indirect costs. One of these systems is the Activity Based Costing System $(\mathrm{ABC})$. The main principle of $\mathrm{ABC}$ is that the activities consume the sources and the activities are consumed by the cost subject. Based on this main principle, there are two phases in the application of $\mathrm{ABC}$ method.

First Phase: The activity-based costing method first defines the activities and then allocates the costs of indirect activities to homogeneously created cost pools. Thus, the indirect costs are divided into categories. These categories should have an easy and understandable physical interpretation and be relatable to the relevant departments in the production process. The costs should be the costs related with these departments. After all these transactions, the indirect costs that are related with each other are combined and a homogeneous cost pool is obtained. In conclusion, it should be possible to explain the changes of costs in the cost pool by using a single cost factor (Mowen ve Hansen, 2011:244-245).

Second Phase: The source costs in the cost pool are allocated to the products by using the cost factors. In order to make this allocation, first, the activity consumed by each product should be measured and then the costs should be allocated to products by using these measurements. In allocating the AICs to the products, the $\mathrm{ABC}$ system uses the assumption "activities consume sources and products consume activities" rather than the production volume principle in conventional system. Thus, the cost drivers are needed in order to allocate the general production costs to the products in $\mathrm{ABC}$. The cost drivers can be defined as the most important factors allowing the establishment of a cause-effect relationship between manufactured products or services and costs (Barfield et al., 1994:178). The selection and use of cost drivers are much more important, especially in today's machine-intensive production trend.

In the present study, the activity drivers were determined based on the opinions of a group of experts rather than obtaining the opinions of a single expert. For this purpose, the cost system of a company, which manufactures folio and is based in Sivas Organized Industrial Zone, was examined. The company currently uses the conventional costing system. In this system, the total amount of costs is allocated to the products directly proportional to the production volumes. In the present study, the Activity-Based Costing System based on the Analytical Hierarchy Process, which enables more accurate calculation of unit product costs, was established and the costs collected in activity drivers were allocated to the activities and products accurately. As a result of this study, it was determined that the unit costs calculated using the conventional costing system and the unit costs calculated using ABC-AHP method were different. In comparison to the method currently used by the company, ABC-AHP method uses the activity processes in calculating the unit costs at the level of product model and, thus, the activity costs differed. Among two types of folios manufactured by the company, $3 \%$ higher unit costs were calculated for the wide folio (WF) and $12 \%$ lower costs for the narrow folio (NF) model. This may cause significant changes in the financial statements depending on the company's sales volume. The wrong pricing may lead the company into several problems in the long-run. For this reason, it is recommended for the administrators to review the costing system. Moreover, in the present study, it was also 
determined in which activity the more expenses were borne. Thus, the administrators would be able to know which activity causes higher costs. In this study, the process of binding was responsible for the half of expenses.

Keywords: Activity-Based Costing, Analytical Hierarchy Process, Unit Cost, Cost

Öz: Yükselen rekabet ortamında firmalar, mamule değer katmayan harcamalardan kaçınma eğilimi içeresindedirler. Mamul maliyetlerinin azaltılması amacı doğrultusunda ise öncelikle, maliyetlerin doğru olarak tespiti önem taşımaktadır Bu çalışmanın amacı, birim mamül maliyetlerinin hesaplanmasında kullanılan Faaliyete Dayaılı Maliyetleme (FDM) yöntemi ve Analitik Hiyerarsi Prosesi (AHP) entegrasyonuyla maliyet sürücülerinde toplanan maliyetlerin faaliyetlere ve mamüllere doğru bir şekilde dağıtılmasını sağlamaktır. Çalışmanın amacına ulaşabilmesi için maliyetlerin dağıtılmasında kullanılacak sürücüler, Analitik Hiyerarşi Prosesi (AHP) yardımıyla belirlenmiş olup yedi farklı uzman, dağıtım anahtarlarını belirlemek için değerlendirmelerde bulunmuşlardır. Araştırma sonucunda; işletmenin geleneksel maliyet muhasebesi ile hesaplamış olduğu birim maliyet ile FDM-AHP tekniği yardımıyla hesaplanan birim maliyetlerin farklı olduğu tespit edilmiştir. FDM-AHP tekniği ile birlikte, işletmenin hâlihazırda kullandığı birim maliyetlerden farklı olarak ürün modeli bazında birim maliyetlerin hesaplamasında faaliyet süreçleri ve kullandıkları faaliyet maliyetlerin farklılaştı̆̆ 1 tespit edilmiştir. İşletmenin ürettiği iki tip model üründen geniş klasör( GK) modeli için \%3 oranında daha yüksek birim maliyet hesaplanırken dar klasör(DK) modeli için ise \%12 oranında düşük birim maliyet hesaplaması gerçekleştirilmiştir. $\mathrm{Bu}$ durum, işletmenin satış hacmine bağlı olarak mali tablolarında önemli değişikliklere neden olabilecektir. Ayrıca çalışmada hangi faaliyetin, daha çok maliyet tükettiği de saptanmıştır. Böylelikle yöneticiler hangi faaliyetin daha çok maliyet tükettiğini de tespit etmiş olacaktırlar.

Anahtar Kelimeler: Faaliyete Dayalı Maliyetleme, Analitik Hiyerarşi Süreci, Birim Maliyet, Maliyet.

\section{Giriş}

Küreselleşmenin etkisiyle artan rekabet şartları işletmelerin kar edebilmesini zorlaştırmaktadır. Kar, gelir ile gider arasındaki olumlu farktır. Rekabetin çetin olduğu durumlarda fiyatları artırmak zor hatta imkânsızdır. Dolayısıyla işletmeler maliyetler üzerinde değişiklik yapma yoluna gideceklerdir. Vergi Usul Kanunu'nun 275. maddesi üretilen mamul maliyetinin (imal edilen emtia) unsurlarını sıralamıştır. Sözkonusu madde hükmü şu şekildedir.

"İmal edilen emtianın (Tam ve yarı mamul mallar) maliyet bedeli aşağıda yazılı unsurları ihtiva eder:

1. Mamulün vücuda getirilmesinde sarf olunun iptidai ve ham maddelerin bedeli,

2. Mamule isabet eden işçilik,

3. Genel imal giderlerinden mamule düşen hisse,

4. Genel idare giderlerinden mamule düşen hisse (Bu hissenin mamulün maliyetine katılması ihtiyaridir.),

5.Ambalaj11 olarak piyasaya arz edilmesi zaruri olan mamullerde ambalaj malzemesinin bedeli."1

Mükellefler, imal ettikleri emtianın maliyet bedellerini yukarıdaki unsurları ihtiva etmek şartıyla diledikleri usulde tayin edebilirler. Direkt ilk madde ve malzeme gideri ve direkt işçilik gideri ürün maliyetlerine doğrudan yüklenebilmektedir. Genel üretim maliyetiyse (GÜM) dolaylı giderlerden oluştuğu için ürün maliyetlerine yüklenmesi daha zor olabilmektedir (Dumanoğlu, 2005:105).

\footnotetext{
${ }^{1}$ Çalışmada işletmeye ait ambalaj giderleri ürün birim maliyetine eklenmemiştir. Nitekim klasör üretiminde ambalaj klasörün mütemmim cüzü (bütünleşik parçası) değildir.
} 
İşletmeler geleneksel maliyetleme yönteminde genel üretim maliyetleri mamullere dağıtılırken birçok sıkıntıyla karşı karşıya kalabilmektedirler. Dolayısıyla mamul maliyetleri çokta sağlıklı oluşturulamamaktadır. Dolaylı maliyetlerin daha doğru şekilde dağıtılabilmesi için çağdaş maliyetleme sistemlerinden yararlanılabilmektedir. Bu sistemlerden birisi de Faaliyete Dayalı Maliyetleme Sistemi (FDM)'dir. FDM sistemi, GÜM'lerini üretilen mamullere yüklerken, geleneksel sistemdeki üretim hacmi ölçüsü yerine, "faaliyetlerin kaynakları, mamullerin de faaliyetleri tükettiği”" varsayımına dayanmaktadır. Dolayısıyla FDM'de genel üretim maliyetlerinin mamüllere yüklenmesi için maliyet sürücülerine ihtiyaç duyulmaktadır.Maliyet sürücüleri üretilen ürünler ya da hizmetler ile maliyetler arasında neden sonuç ilişkisi kurulmasını sağlayan en önemli faktörler olarak tanımlanabilir (Barfield vd.,1994:178). Maaliyet sürücülerin seçimi ve kullanılması bilhassa günümüz makine yoğun üretim biçiminde çok daha fazla önem kazanmaktadır.

$\mathrm{Bu}$ çalışmada faaliyet sürücüleri, sadece bir uzman görüşü yerine, bir grup uzmanın değerlendirmelerini dikkate almak suretiyle belirlenmiştir. Bu amaçla; Sivas Organize Sanayi Bölgesi'nde faaliyetlerini sürdüren bir klasör üretim işletmesinin maliyet sistemi incelenmiştir. İşletme hâlihazırda geleneksel maliyet sistemini kullanmaktadır. Kullandıkları sistemde, toplam maliyet tutarı ürünlere üretim miktarları ile doğru orantılı olarak dağıtılmaktadır. Çalışmada söz konusu işletmenin birim mamul maliyetinin daha doğru hesaplanmasını sağlayan Analitik Hiyerarşi Prosesi temelli Faaliyete Dayalı Maliyetleme sistemini kurarak ve faaliyet sürücülerinde toplanan maliyetlerin faaliyetlere ve mamullere doğru bir şekilde dağıtılması sağlanmıştır.

\section{Literatür Taraması}

$\mathrm{Bu}$ çalışmanın konusuyla ilgisi bulunan diğer çalışmalardan bazılarına ait özet bilgiler şöyledir:

Merchant ve Shields (1993) faaliyete dayalı maliyetlemede en uygun maliyet anahtarı seçimini incelediği çalışmasında, en uygun maliyet anahtarının seçimi için matematiksel bir yöntem geliştirmişlerdir. Literatürden farklı olarak ihtiyaç duyulan yere sadece bir maliyet anahtarı değil birden fazla maliyet anahtarı önerebilen bir yaklaşım kullanmışlardır ve çalışmada önerilen bu yöntemin karmaşık faaliyete dayalı maliyetleme sistemlerinde daha doğru maliyet dağıtımı sağladığı tespit edilmiştir.

Babad ve Balachandran (1993) çalışmalarında, faaliyete dayalı maliyetleme sisteminde ne tür ve kaç adet maliyet anahtarı kullanılacağını belirlemek amacıyla bir optimizasyon modeli geliştirmişlerdir. Araştırmacılar çalışmalarında Greedy algoritması kullanmışlardır. Araştırma sonucunda eğer iki veya daha fazla maliyet anahtarı birbirleri ile mükemmel korelasyona sahip ise bir araya getirilebilirler ve bu işlemle veri kalitesinde herhangi bir bozulmanın olmadığını tespit etmişlerdir. Buna ek olarak maliyet anahtarı sayısı azaldığı için ölçüm maliyetlerinde de azalma bekleneceği tespit edilmiştir.

Baykasoğlu ve Kaplanoğlu (2008) çalışmalarında, FDM tekniğini, Türkiye'de faaliyet gösteren bir karayolu lojistik firmasına uygulamışlardır. FdM'nin etkinliğini arttırmak için FDM'yi iş süreci modelleme ve analitik hiyerarşi yaklaşımı ile birleştiren bir bütünleşik yaklaşım önermişlerdir. Önerilen yaklaşımın, firmanın maliyetlendirme hizmetlerinde, mevcut geleneksel maliyetleme sistemine kıyasla oldukça etkili olduğunu belirlemişlerdir.

Esmeray ve Tanç (2009) çalışmalarında, Kayseri'de faaliyet gösteren bir sanayi işletmesi üzerinde çevresel maliyetlerin mamullere yüklenmesinde dağıtım anahtarlarının seçiminde Faaliyete Dayalı Maliyetleme (FDM) yöntemi ve Analitik Hiyerarşi Prosesi (AHP) entegrasyonu kullanmışlar ve yöntemin etkinliğini yapılan uygulama ile de doğrulamaya çalışmışlardır.

Karataş vd. (2014) çalışmalarında, Z İnşaat Taahhüt işletmesinin gerçek maliyet verilerinden yaralanılarak yine aynı sektörde faaliyet göstermesi planlanan farazi bir K İnşaat Taahhüt işletmesi 
için tahmini maliyet yapısı oluşturmuşlardır. Elde edilen verilerden hareketle bulanık tahminleme, FDM yöntemi ile birleştirilerek bulanık verilerle oluşturulan aynı ölçekteki K inşaat taahhüt işletmesi için bir ihalede teklif verirken kullanabileceği bir maliyet tahmin modeli geliştirilmiştir.

Shashikumar vd. (2017) çalışmalarında, üretim tesisi yerleşke alternatiflerinin değerlendirilmesinde FDM ve AHP tabanlı bir sistem uygulamışlardır. Sonuçta; beş alternatif arasından en iyi alternatifi belirledikleri raporlanmaktadır. Alternatif sayısı çoğaltıldığında bile modelin etkin bir şekilde sıralama gerçekleştireceği Raporlanmıştır.

Can vd. (2018) çalışmalarında, genel imalat maliyetlerini, maliyet anahtarı kullanarak ürünlere dağıtan maliyet sistemleri kullanan işletmelerin, maliyet anahtarı seçimi işlemi sırasında doğru ve uygun maliyet anahtarını seçebilmelerine olanak sağlayan altı adet birbirini destekleyen seçim kriteri kullanan bütünleşik bir maliyet anahtarı seçim modeli önermişlerdir. Bu modelde çok kriterli karar verme tekniklerinden Analitik Hiyerarşi Süreci, TOPSIS ve MOORA bütünleşik olarak kullanılmaktadır. Modelde kullanılan karar kriterleri ve alternatifleri Analitik Hiyerarşi Süreci yöntemi kullanılarak ağırlıklandırılmaktadır. Bütünleşik model için yapılacak olan uygulamanın sonucunda modelde kullanılan yöntemlerden elde edilen sıralamalar ile alternatif maliyet anahtarları arasından genel imalat maliyetlerinin dağıtımı için gerekli en uygun maliyet sürücüsü seçilmiştir.

Özçalıcı ve Kaya (2019) çalışmalarında, birim mamul maliyetinin daha doğru hesaplanmasını sağlayabilecek Analitik Hiyerarşi Prosesi temelli Faaliyete Dayalı Maliyetleme sistemini kurmak ve faaliyet sürücülerinde toplanan maliyetlerin faaliyetlere ve mamullere doğru bir şekilde dağıtılmasını sağlamayı amaçlamışlardır. Araştırma sonucunda, FDM-AHP tekniği ile hesaplanan birim maliyetler ile işletmenin kullandığ maliyetler arasında farklılıklar olduğu tespit edilmiştir.

\section{Faaliyet Tabanlı Maliyet Sisteminin Tanımı ve Amacı}

Günümüzde küresel gelişmeler rekabet ve teknoloji alanlarında köklü değişimleri beraberinde getirmiştir. $\mathrm{Bu}$ değişim üretim sistemlerinde de kendini hissettirmiştir. Üretim sistemlerindeki değişim maliyet unsurunun üzerinde durulmas1 gereken en önemli bir konu olarak karşımıza çıkmaktadır. Maliyet yönetim anlayışı, firmanın önemli faaliyetlerinin maliyetlerini değerlendirmeye, gereksiz maliyet kalemlerini ölçmeye ve firma performansında olumlu yönde katkı sağlayacak bir takım faaliyetleri keşfetmeye çalışmaktadır. Bu anlayışla faaliyetler üzerinde durularak kaliteli fakat ucuz mamulü üretmek gibi nihai bir hedefe yönlenilmiştir. Teknolojik gelişmelerin maliyet yönetimine getirdiği bu yeni yöntem faaliyete dayalı maliyetleme olarak nitelendirilmektedir (Abdioğlu, 2012: 277).

FDM sistemi; "stratejik, tasarım, faaliyet kontrolü ve mamul grupları ile ilgili tüm kararların alınmasında maliyet bilgisini sağlayan ve bu faaliyetlerle ilgili maliyetleri mamullere ve/veya mamul gruplarına kullandıkları faaliyet oranında pay veren bir maliyet sistemidir "(Barnes, 1992: 21). FDM sisteminde Genel Üretim Maliyetlerinin oluşumuna sebep olan faaliyetleri esas alan ve söz konusu maliyetleri mamullere yüklerken tek bir yükleme oranı yerine her bir faaliyet için farklı yükleme oranını temel alan bir sistemdir.

FDM sistemi, biçimsel olmaktan çok stratejik amaçları bünyesinde barındıran muhasebe sistemi şeklinde de tanımlanmaktadır. (Cooper ve Kaplan, 1988: 97).Bu bağlamda FDM işletme yönetimine klasik maliyetleme bilgisinden ziyade işletmeye ilişkin faaliyetlerin maliyetleriyle ilgili detaylı bilgi sunmaktadır. 2013:51) :

Yukarıda anlatılanlardan hareketle FDM sisteminin amaçları şöyledir (Shatnawi ve Hardan,

> Gerçekleştirilen analiz ve çalışmalar neticesinde, faaliyetler sonucu vuku bulan maliyetleri ölçebilmeyi, 
İşletme için değerli olan faaliyetlerden gereksiz faaliyetleri açılayarak faaliyetlerin dizaynını gerçekleştirebilmeyi,

$>$ İşletmenin sürdürülebilir kar elde etmesini sağlamak için stratejik planların geliştirilmesini,

$>$ Probleme sebep olan sorunların ana sebeplerini araştırıp problemlerin ortadan kaldırılmasını sağlamaktır.

$\mathrm{Bu}$ amaçları gerçekleştirmek, işletme yönetiminin ürettiği ürünler veya sunduğu hizmetler hakkında daha net bilgilere sahip olmasına katkı sağlayacak, hangifaaliyetlerin katma değeri yüksek hangilerinin katma değerinin düşük olduğunu ve işletmenin hangi faaliyetlere yönelmesi gerektiğini ortaya koyacaktır.

\section{Faaliyet Tabanlı Maliyetleme Sistemini Oluşturan Temel Unsurlar}

FDM'nin daha iyi anlaşıılması açısından, bu yaklaşımın içerisinde önemli araçlar olan temel kavramların tanımlanması ve açıklanması önemlilik arz etmektedir. Bu kavramlar:

Kaynaklar:"İşletmelerin, üretim süreçlerinin oluşumunda yer alan faaliyetlerin tamamlanabilmesi amaciyla gerekli olan ekonomik unsurlar olarak" ifade edilmektedir (Büyükşalvarcı, 2006:165).

Faaliyet:"Planlanan bir işlemin icrasına dair gerçekleştirilen ve gerçekleştirilmesi planlanan işlemler bütünüdür" (Garrison ve Noreen, 1994:193).Faaliyetler, "işletme ya da fabrika içerisinde, uzmanlaşmış personellerden oluşan çalışma grupları ya da merkezler tarafindan yapılan yinelemeler sonucunda gerçekleştirilen ve dolayısıyla kendi sürecini oluşturmuş işlerdir" (Zimmerman, 2011:506)

Faaliyet Hiyerarşisi: Faaliyetlere kimlik kazandırılması ile eş anlamda kullanılan "faaliyet hiyerarşisi”, maliyetlerin ortaya çıktığı düzeye göre faaliyetlerin sınıflandırılması için oluşturulan bir çerçeve sunar (Arzova 2002:5-7).

Faaliyet merkezleri: Bir işletme için önem taşıyan faaliyetlerin bir arada toplandığı yerler olarak tanımlanmaktadır.

Maliyet havuzları: "İş̧letmede meydana gelen faaliyetleri bireysel maliyetler şeklinde sınıflayarak tek bir maliyet havuzda toplama işlemidir. Başka bir ifade ile faaliyetlerin tükettiği kaynakların toplam miktarlarının faaliyetler açısından belirlenmesi işlemine "maliyet havuzu" oluşturma denmektedir" (Gümüş, 2007:71).

Maliyet Objesi: Muhasebe biliminde maliyeti belirlenen unsurlar "Maliyet Objesi " olarak adlandırılır. Bu işlem sonuçlara yönelik olabileceği gibi faaliyetlere yönelikte olabilir. İşletmeler, maliyet bilgilerine ihtiyaç duymalarına sebep olan farklı maliyet objeleriyle karşılaşabilirler. Mesela, "satın alınan bir malın, üretilen bir mamulün, sağlanan bir hizmetin, üretim yapan bir atölyenin ve daha pek çok şeyin maliyetini saptamak söz konusu olabilir” (Büyükmirza, 2010: 44-45).

Maliyet Sürücüsü:"Maliyet sürücüleri; işletmelerin esas faaliyetleri sonucu elde ettikleri çıktıların maliyet değerlerini belirlemelerinde etkili olan ayrıca faaliyetler sonucu oluşan maliyetler ile faaliyet arasında köprü görevi üstlenen kavram şeklinde açıklanmaktadır” (Köse, 2005:130). En iyi maliyet sürücüsü dağıtılan maliyetle ilşkilendirilen sürücüdür. Geleneksel maliyetleme yönteminde maliyet sürücüsü olarak " direkt işçilik saati veya makine saati” gibi dağıtım anahtarları kullanılırken FDM yönteminde " faaliyet hacmini temel alan maliyet anahtarları" kullanılmaktadır (Lanen vd., 2011:321). Maaliyet sürücülerini aşağıda belirtilen iki maddede özetlemek mümkündür(Köse, 2005: 130):

a) Kaynak maliyet sürücüsü: Bu maliyet sürücüsü faaliyetlerin tüketebildiği kaynaklara göre hesaplama yapmaktadır. Dolayısıyla kaynak maliyet sürücüsü maliyet havuzlarında kullanılmış 
kaynakları hesap etmektedir. Bir faaliyetin ne miktarda kaynak kullandığını ortaya koyan maliyet sürücüsüdür.

b) Faaliyet maliyet sürücüsü: Maliyet havuzlarında maliyetleri ilgili faaliyetlere dağıtan maliyet sürücüsüdür. $\mathrm{Bu}$ duruma, üretilen bir ürünün üretim aşamasında kullanılması gereken makinaların kaç saat çalıştığ 1 örnek verilebilir.

Yukarıdaki açıklamalar doğrultusunda Tablo 1'de faaliyete dayalı maliyetleme sistemini oluşturan temel unsurlarverilmiştir.

Tablo1: Araştırmada Faaliyete Dayalı Maliyetleme Sistemini Oluşturan Temel Unsurlar

\begin{tabular}{|c|c|c|c|c|}
\hline Faaliyetler & Faaliyet Hiyerarşisi & Faaliyet Mekezi & Maliyet Havuzu & Maliyet Objesi \\
\hline Satın Alma & Satın Alma & \multirow{6}{*}{$\begin{array}{c}\text { Klasör Üretim } \\
\text { Hattı }\end{array}$} & \multirow{6}{*}{$\begin{array}{c}\text { Endirek ve Direk } \\
\text { Giderlerin } \\
\text { Toplamı }\end{array}$} & \multirow{6}{*}{$\begin{array}{c}\text { Üretim Miktarı } \\
\text { AHP Kriter } \\
\text { Ağırlıkları }\end{array}$} \\
\hline Mukavvanın Ebatlanması & Mukavvanın Ebatlanması & & & \\
\hline Klasörün Ciltlenmesi & Klasörün Ciltlenmesi & & & \\
\hline Klasör Katlama & Klasör Katlama & & & \\
\hline $\begin{array}{c}\text { Klasöre Mekanizmanın } \\
\text { Çakılması }\end{array}$ & $\begin{array}{c}\text { Klasöre Mekanizmanın } \\
\text { Çakılması }\end{array}$ & & & \\
\hline $\begin{array}{l}\text { Klasör Etiket (Cep) } \\
\text { Yapıştırılması }\end{array}$ & $\begin{array}{l}\text { Klasör Etiket (Cep) } \\
\text { Yapıştırılması }\end{array}$ & & & \\
\hline
\end{tabular}

\section{Faaliyet Tabanlı Maliyetleme Yönteminin Uygulama Süreci}

Faaliyete dayalı maliyetleme sisteminin ana kuralı faaliyetlerin kaynakları tükettiği, faaliyetlerin ise maliyet objesi tarafından tüketildiğidir. Bu ana kuraldan yola çıkarak faaliyete dayalı maliyet sisteminin uygulanmasında iki aşama vardır.

Birinci Aşama: Faaliyete dayalı maliyetleme sistemi ilk etapta faaliyetleri tanımlayarak dolaylı faaliyetlere ilişkin maliyetleri homojen bir şekilde oluşturulan maliyet havuzlarına dağıtır. Endirek maliyetler böylelikle kategorilere ayrılır. Söz konusu kategoriler kolay ve anlaşılır bir fiziksel yorumlamaya sahip olmalıdır ve üretim sürecindeki uygun bölümlerle ilişkilendirilebilmelidir. Maliyetlerse bu bölümlerle ilgili maliyet olmalıdır. Tüm bu işlemlerden sonra birbiriyle ilişkisi bulunan dolaylı maliyetler bir araya getirilerek homojen bir maliyet havuzu oluşur. Sonuç olarak maliyet havuzunda maliyet değişimleri bir tek maliyet etkeni ile açıklanmalıdır (Mowen ve Hansen, 2011:244-245).

İkinci Aşama: Maliyet havuzlarındaki kaynak maliyetleri ikinci aşamadaki maliyet etkenleri kullanılarak ürünlere dağıtılır. Bu yüklemenin yapılabilmesi için, ilk olarak her ürünün tükettiği faaliyet miktarını ölçüp, daha sonra bu ölçüleri kullanılarak maliyetleri ürünlere yüklenmesi gerekmektedir(Taşç1, 2004:46).

\section{Analiz}

\subsection{Analitik Hiyerarşi Proses(AHP)}

Analitik Hiyerarşi Süreci (AHP) 1970'li y1llarda Wharton School of Business'da Thomas L. Saaty tarafından karmaşık çok kriterli karar verme problemlerinin çözümü için geliştirilmiştir (Saaty ve Vargas, 2012:3). Bu yöntem Saaty tarafından geliştirilen ikili karşılaştırma anketi, hem kesikli hem de sürekli değerlerden oluşan ikili karşılaştırmaları oran ölçeğine dönüştürerek Analitik Hiyerarşi Süreci'nin ilk adımı olan karşılaştırma matrisinin oluşturtmasını sağlamaktadır. İkili karşılaştırma matrisi oluşturulur. 


$$
A=\left[\begin{array}{ccc}
a_{11} & \cdots & a_{1 n} \\
\vdots & \ddots & \vdots \\
a_{n 1} & \cdots & \text { ann }
\end{array}\right]
$$

Şekildeki gibi oluşturulur. Bu aşamada normalize matris oluşturulmak için ikili karşılaştırma matrisinin her bir elamanı satır toplamına bölünerek B normalize matris elde edilir. Normalize matrisin satır ortalamaları w ağırlık vektörü olarak hesaplanmaktadır. Bu aşamadan sonra hesaplan ikili karşılaştırma matrisinin tutarlı olup olmadığını belirlemek üzere ikili karşılaştırma matrisi A ile w ağırlık vektörü çarpılarak e vektörü elde edilir. Hesaplanan e vektörü değerlerinin toplamı faaliyet sayısına bölünerek " $\left(\lambda_{\max }=\frac{\sum_{i=1}^{n} e}{n}\right)$ ” $\lambda_{\max }$ değeri elde edilir. Sonrasında CI değeri formülü yardımıyla $C I=\frac{\lambda-n}{n-1}$ hesaplandıktan sonra kriter sayısına göre belirlenen Random Indeks (RI) tablo değerine bölünerek tutarlılık değeri olan CR değeri $\left(C R=\frac{C I}{R I}\right)$ formülü ile hesaplanmaktadır. Hesaplanan CR < 0,10'da küçük olduğunda ikili karşılaştırmaların tutarlı; büyük olduğunda ise tutarsız olduğu söylenebilir.

\subsection{Veri Seti}

Çalışmada, Sivas Organize Sanayi Bölgesin de üretim faaliyetinde bulunan bir işletmenin, 1 Ocak 2018 ve 31 Aralık 2018 tarihli dönemi inceleme altına alınmıştır. İşletmenin birden fazla ürün üretimi söz konusu olduğu için faaliyet alanlarından biri olan klasör üretimine yönelik faaliyetler incelemeye alınmıştır. İşletme, 400 adet günlük 124.800 adet y1llık klasör üretimi yapmaktadır. Bu üretimin dörtte biri dar klasör (DK) iken geriye kalanı geniş klasör (GK) olarak üretilmektedir. Yapılan görüşmelerde, işletmenin isminin gizli kalması talep edilmiştir. Bu nedenle çalışmada şirket hakkında özel bilgilere yer verilmeyecektir.

Faaliyet Tabanlı Muhasebenin uygulanması için ihtiyaç duyulan maliyet bilgileri, muhasebe kayıtlarından ve işletme yöneticisi ile yapılan görüşmelerden derlenmiştir. İşletmenin ana faaliyetleri iki grupta toplanmıştır. Bu gruplar; satın alma faaliyeti ve üretim faaliyetidir. Üretim faaliyeti de kendi içinde beş alt faaliyetten oluşmaktadır. Bu üretim alt faaliyetleri; ebatlama, ciltleme, klasör katlama, mekanizmanın çakılması ve etiket (cep) yapıştırılması faaliyetleridir. İşletmenin incelemeye alınan faaliyetleri Tablo 2.'de listelenmiştir.

Tablo 2: İşletmenin Faaliyetleri

\begin{tabular}{|l|l|}
\hline Kısaltma & Faaliyet İsmi \\
\hline S1 & Satın Alma \\
\hline K2 & Mukavvanın Ebatlanması \\
\hline K3 & Klasörün Ciltlenmesi \\
\hline K4 & Klasör Katlama \\
\hline K5 & Klasöre Mekanizmanın Çakılması \\
\hline K6 & Klasör Etiket (Cep) Yapıştırılması \\
\hline
\end{tabular}

Tablo 3.’te ürünlere ilişkin bilgiler yer almaktadır. İşletme iki çeşit ürün üretmektedir.

Tablo 3: Ürünlere İlişkin Bilgiler

\begin{tabular}{|l|l|}
\hline Ürün Kodu & Niteliği \\
\hline DK(31*61) & Dar Klasör \\
\hline GK $\left(\mathbf{3 1}^{*} \mathbf{6 4}\right)$ & Geniş Klasör \\
\hline
\end{tabular}

İşletme ürettiği ürünler için detaylı maliyet kaydı tutmamaktadır. Hâlihazırda ürünlerin birim maliyetleri geleneksel maliyet yöntemine göre hesaplamaktadır. İşletme birim maliyetine direk ilk madde malzeme direkt işçilik ve genel üretim maliyetlerini yüklemektedir. Birim maliyet hesaplanırken direk ilk madde ve malzeme maliyeti ile direk iş̧̧ilik maliyetini mamullere 
yüklemektedir. Genel üretim maliyetleri hesaplanırken, endirekt maliyet toplamı, ürünlere, üretim miktarına (Adet) göre dağıtılmaktadır.

Yapılan görüşmeler sonucunda; ürün bazında izlenemeyen giderler (Endirekt Giderler): Elektrik Gideri, Makine Bakım Gideri, Amortisman Giderleri ve Diğer Giderler olmak üzere dört grupta toplanmıştır. Ürün bazında ekonomik olarak takip edilebilen maliyetler ise Direkt İşçilik Giderleri, Direkt İlk Madde Malzeme Gideri iki çeşittir. Dönem içerisindeki gider türleri ve tutarları Tablo 4'te sunulmuştur. Dönem içerisinde işletmenin endirekt giderlerinin payı toplam giderler içerisinde yaklaşık \%6,18'lik payı kaplamaktadır, geri kalan $\% 93,82$ ' lık pay ise direkt giderlere aittir.

Tablo 4: Direkt ve Endirekt Dönem Giderleri

\begin{tabular}{|l|l|l|l|}
\hline $\begin{array}{l}\text { Gider } \\
\text { Türü }\end{array}$ & Açıklama & $\begin{array}{l}\text { Dönem Gideri } \\
(\text { ( ) }\end{array}$ & $\begin{array}{l}\text { Yüzde } \\
(\boldsymbol{\%})\end{array}$ \\
\hline \multirow{4}{*}{ Endirekt } & Elektrik Gideri & $10.332,32$ & \\
\cline { 2 - 4 } & Tamir-Bakım & $1.123,12$ & \\
\cline { 2 - 4 } & Amortisman & $21.540,10$ & \\
\cline { 2 - 4 } & Diğer Giderler & $1.353,10$ & \\
\cline { 2 - 4 } & Toplam Endirekt Giderler & $\mathbf{3 4 . 3 4 8 , 6 4}$ & $\% 6,18$ \\
\hline \multirow{3}{*}{ Direkt } & Direkt İşçilik Giderleri & $67.817,43$ & \\
\cline { 2 - 4 } & Direkt İlk Madde ve Malzeme Gideri & $453.953,55$ & \\
\cline { 2 - 4 } & Toplam Direkt Giderler & $\mathbf{5 2 1 . 7 7 0 , 9 8}$ & $\% 93,82$ \\
\hline Toplam & (Endirekt + Direkt) & $\mathbf{5 5 6 . 1 1 9 , 6 2}$ & $\% 100$ \\
\hline
\end{tabular}

Her faaliyet her gideri kullanmamaktadır. Tablo 5'de faaliyetlerin giderlerle ilişkilendirilmesi yer almaktadır. Tablo 5'de ilk sırada yer alan elektrik gideri ve son sırada yer alan diğer giderler her faaliyet ile ilgilidir.

Tablo 5: Faaliyetler ve Gider Kalemleri

\begin{tabular}{|c|c|c|c|c|c|c|}
\hline & $\begin{array}{c}\text { Satın } \\
\text { Alma }\end{array}$ & Ebatlama & Ciltleme & Katlama & $\begin{array}{c}\text { Mekanizmanın } \\
\text { Çakılması }\end{array}$ & $\begin{array}{c}\text { Cep } \\
\text { Etiketi }\end{array}$ \\
\hline Elektrik Gideri & & + & + & + & + \\
\hline Tamir Bakım Gideri & & + & + & + & + & + \\
\hline Amortisman & & + & + & + & + & + \\
\hline Diğer Giderler & + & + & + & + & + \\
\hline Elektrik Gideri & & + & + & + & + \\
\hline
\end{tabular}

\section{Uygulama}

Genel gider niteliğindeki giderlerin ürünlere dağıtılması iki aşamada gerçekleştirilmiştir. İlk olarak giderlerin, kaynak sürücüleri yardımıyla faaliyetlere yüklenmesi ve ikinci adımda da faaliyet havuzunda toplanan giderlerin, faaliyet sürücüleri yardımıyla ürünlere yüklenmesi aşamasıdır. Her iki aşamada da sürücüler AHP tekniği yardımıyla hesaplanmıştır.

Çok Kriterli Karar Verme (ÇKKV) problemlerinde kriter ağırlıkları ve kullanılan yöntem problemin çözümüne doğrudan etki etmektedir (Özçalıcı ve Kaya, 2019: 342). Bu nedenle sadece bir uzmanın gerçekleştireceği değerlendirmeleri dikkate almak, sonuçların yanlı olmasına neden olacaktır. Çalışmada, 6 farklı uzmanın değerlendirmeleri dikkate alınmıştır. Bu şekilde farklı görüşler bir araya getirilmiş ve görüşler arasında uzlaşı geometrik ortalama yardımıyla sağlanmıştır. İşletme faaliyetlerini yakından tanıyan ve üretimden sorumlu 2 uzman, 1 işletme yöneticisi, işletme faaliyet ve süreçlerini bilen 2 akademisyen ve 1 işletme muhasebecisi olmak üzere toplam 6 kişi AHP formlarını birbirlerinden bağımsız bir şekilde değerlendirmişlerdir. Her uzman, faaliyet 
havuzunda toplanan faaliyetlerin, gider havuzunda toplanan dört farklı gider türünü ne ölçüde kullandığını ikili karşılaştırmalar yardımıyla değerlendirmeye tabi tutmuştur.

\section{Belirlenmesi)}

6.1. Giderlerin Faaliyetlere Yüklenmesi Süreci (I. Aşama) (Kaynak Sürücülerinin

$\mathrm{Bu}$ aşamada endirekt giderler faaliyetlere atanmaktadır. Bu atama işleminde kullanılacak sürücü değerleri, AHP değerlendirme matrisleri yardımıyla hesaplanmaktadır.

\subsubsection{Elektrik Giderlerin Faaliyetlere Yüklenmesi}

Elektrik gideri, firmanın abone olduğu elektrik dağıtım şirketinin söz konusu yıl içerisinde faturaladığı tutardır. Faaliyetin elektrik giderini ne kadar kullandığına ilişkin yedi farklı uzmanın gerçekleştirdiği ikili karşılaştırma formundan elde edilen değerlendirmelerin geometrik ortalaması alınarak ikili karşılaştırma matrisleri oluşturulmuştur. Çalışma boyunca her bir gider kalemi için benzer ikili karşılaştırma matrisleri oluşturularak tutarsızlık değerleri ve sürücü katsayıları benzer şekilde hesaplanmıştır. Çalışmada her hesaplamaya yer vermek çalışmanın hacmini genişleteceği için sadece bir hesaplama örneğinin detaylarını aşağıdaki şekilde sunulmuştur.

Elektrik giderine ilişkin uzmanların değerlendirmesi sonucunda elde edilen A karşılaştırma matrisi aşağıda gösterildiği gibidir.

$\begin{array}{cccccc}\text { Kriterler } & \text { Ebatlama } & \text { Ciltleme } & \text { Katlama } & \text { M. Çakılması } & \text { Cep Etiketi } \\ \text { Ebatlama } & 1,000 & 0,286 & 4,527 & 1,969 & 2,060 \\ \text { Ciltleme } & 3,497 & 1,000 & 6,055 & 5,664 & 5,422 \\ \text { Katlama } & 0,221 & 0,165 & 1,000 & 0,421 & 0,394 \\ \text { M.Çakılması } & 0,508 & 0,177 & 2,375 & 1,000 & 0,841 \\ \text { Cep Etiketi } & 0,485 & 0,184 & 2,538 & 1,189 & 1,000 \\ \text { Toplam } & 5,711 & 1,812 & 16,495 & 10,243 & 9,717\end{array}$

$\mathrm{Bu}$ matriste her bir değeri sütun toplamına bölmek suretiyle normalize B matrisi elde edilir.

$B=\begin{array}{cccccc}\text { Kriterler } & \text { Ebatlama } & \text { Ciltleme } & \text { Katlama } & \text { M. Çakllması } & \text { Cep Etiket } \\ \text { Ebatlama } & 0,175 & 0,158 & 0,274 & 0,192 & 0,212 \\ \text { Ciltleme } & 0,612 & 0,552 & 0,367 & 0,553 & 0,558 \\ \text { Katlama } & 0,039 & 0,091 & 0,061 & 0,041 & 0,041 \\ \text { M.Çakllmasl } & 0,089 & 0,097 & 0,144 & 0,098 & 0,087 \\ \text { Cep Etiketi } & 0,085 & 0,102 & 0,154 & 0,116 & 0,103\end{array}$

Elde edilen normalize matrisin satır ortalamaları hesaplanarak faaliyetlere ilişkin yüzdelik ağırlık değerleri belirlenmektedir ve w ağırlık vektörü ile aşağıda gösterilmiştir.

$W=\begin{array}{cc}\text { Kriterler } & \text { Ortalama } \\ \text { Ebatlama } & 0,203 \\ \text { Ciltleme } & 0,528 \\ \text { Katlama } & 0,054 \\ \text { M. Çakllmasi } & 0,103 \\ \text { Cep Etiketi } & 0,112\end{array}$


Tutarsızlık katsayısının hesaplanmasında kullanılacak olan $\lambda_{\max }$ değeri, Amatrisi ile $\bar{w}$ vektörünün matris çarpımı ile hesaplanmaktadır.

$$
\left[\begin{array}{lllll}
1,000 & 0,286 & 4,527 & 1,969 & 2,060 \\
3,497 & 1,000 & 6,055 & 5,664 & 5,422 \\
0,221 & 0,165 & 1,000 & 0,421 & 0,394 \\
0,508 & 0,177 & 2,375 & 1,000 & 0,841 \\
0,485 & 0,184 & 2,538 & 1,189 & 1,000
\end{array}\right] \times\left[\begin{array}{c}
0,202 \\
0,528 \\
0,054 \\
0,103 \\
0,112
\end{array}\right]=\left[\begin{array}{c}
1,033 \\
2,755 \\
0,274 \\
0,522 \\
0,568
\end{array}\right]
$$

Çarpılması sonucunda elde edilen e vektörü aşağıdaki gibidir.

$$
\left.e=\begin{array}{c|c}
\text { Ebatlama } & 1,033 \\
\text { Çiltleme } & 2,755 \\
\text { Katlama } & 0,274 \\
\text { M. Çakllması } & 0,522 \\
\text { Cep Etiketi } & 0,568 \\
\text { Toplam } & 5,152
\end{array}\right]
$$

Hesaplanan e değerinin toplam değeri faaliyet sayısına bölünerek $\lambda_{\max }$ değeri $\lambda_{\max }=$ $\frac{\sum_{i=1}^{n} e}{n}=\frac{5,152}{5}=1,030$ olarak hesaplanır. Sonrasında $\quad C I=\frac{\lambda-n}{n-1}=\frac{5,152-5}{5-1}=0,038$ olarak hesaplandıktan sonra kriter sayısına göre Random Indeks (RI) tablo değerine bölünerek tutarlılık değeri olan CR değeri hesaplanmaktadır. 5 faaliyet için RI değeri 1,120 olarak alınmış (https://www.researchgate.net/figure/Random-Consistency-Index_tbl1_323114042) ve $C R=\frac{C I}{R I}=$ $\frac{0,038}{1,120}=0,034$ olarak hesaplanır. $\mathrm{CR}<0,10$ olduğu için değerlendirmelerin tutarlı olduğu söylenebilir.

Elektrik giderlerin faaliyetlere dağıtılmasında kullanılacak sürücüler faaliyetlere ilişkin hesaplanan (w) ağırlık değerleridir. Bu değerler aşağıda verilmiştir.

$$
w=\begin{array}{cc}
\text { Kriterler } & \text { Ortalama } \\
\text { Ebatlama } & 0,203 \\
\text { Ciltleme } & 0,528 \\
\text { Katlama } & 0,054 \\
\text { M.Çakılması } & 0,103 \\
\text { Cep Etiketi } & 0,112
\end{array}
$$

\subsubsection{Tamir Bakım Giderinin Faaliyetlere Yüklenmesi}

İşletmenin bir yıl içerisinde, makinelerde yaşanan arıza ve aksaklıklar sonucunda yedek parça, tamir ve bakım harcamalarının toplamıdır. Her bir faaliyette kullanılan makinelerin arıza sıklığına ilişkin uzmanların ikili karşılaştırmalarının geometrik ortalaması alınmak suretiyle elde edilen ikili karşılaştırma matrislerinin çözümü sonucunda tutarsızlı değeri $C R=\frac{C I}{R I}=\frac{0,089}{1,120}=$ 0,079 olarak hesaplanır. $\mathrm{CR}<0,10$ olduğu için değerlendirmelerin tutarlı olduğu söylenebilir. Tamir bakım giderlerin faaliyetlere dağıtılmasında kullanılacak sürücüler faaliyetlere ilişkin hesaplanan (w) ağırlık değerleridir. Bu değerler aşağıda verilmiştir. 


$$
w=\begin{array}{cc}
\text { Kriterler } & \text { Ortalama } \\
\text { Ebatlama } & 0,207 \\
\text { Ciltleme } & 0,508 \\
\text { Katlama } & 0,051 \\
\text { M. Çakılmasl } & 0,077 \\
\text { Cep Etiketi } & 0,157
\end{array}
$$

\subsubsection{Amortisman Giderlerin Faaliyetlere Yüklenmesi}

Amortisman, bir varlığın kullanım ve zamana bağlı olarak niceliksel ve niteliksel kalitesinde kademeli olarak sürekli ve kalıcı azalma olarak tanımlamak mümkündür. (http://www.accountingformanagement.com 03.01.2020).Bu gidere ilişkin uzmanların ikili karşılaştırmalarının geometrik ortalaması alınmak suretiyle elde edilen ikili karşılaştırma matrislerinin çözümü sonucunda tutarsızlık değeri $C R=\frac{C I}{R I}=\frac{0,104}{1,120}=0,093$ olarak hesaplanır. CR $<0,10$ olduğu için değerlendirmelerin tutarlı olduğu söylenebilir. Amortisman giderlerin faaliyetlere dağıtılmasında kullanılacak sürücüler faaliyetlere ilişkin hesaplanan (w) ağırlık değerleridir. Bu değerler aşağıda verilmiştir.

$$
w=\begin{array}{cc}
\text { Kriterler } & \text { Ortalama } \\
\text { Ebatlama } & 0,101 \\
\text { Ciltleme } & 0,524 \\
\text { Katlama } & 0,071 \\
\text { M. Çakılması } & 0,148 \\
\text { Cep Etiketi } & 0,156
\end{array}
$$

\subsubsection{Diğer Giderlerin Faaliyetlere Yüklenmesi}

Diğer gider kaleminde ise, ürün bazında ekonomik olarak izlenemeyen muhtelif üretim giderleri yer almaktadır (Özçalııı ve Kaya, 2019: 345). Her bir faaliyetin, diğer gider kalemini kullanma düzeylerine ilişkin uzmanların ikili karşılaştırma değerleri sonucunda elde edilen ikili karşılaştırma matrislerinin çözümü sonucunda tutarsılılı değeri $C R=\frac{C I}{R I}=\frac{0,045}{1,240}=0,036$ olarak hesaplanır. $\mathrm{CR}<0,10$ olduğu için değerlendirmelerin tutarlı olduğu söylenebilir. Diğer giderlerin faaliyetlere dağıtılmasında kullanılacak sürücüler faaliyetlere ilişkin hesaplanan (w) ağırlık değerleridir. Bu değerler aşağıda verilmiş̧tir.

$$
w=\begin{array}{cc}
\text { Kriterler } & \text { Ortalama } \\
\text { Satın Alma } & 0,227 \\
\text { Ebatlama } & 0,370 \\
\text { Ciltleme } & 0,079 \\
\text { Katlama } & 0,117 \\
\text { M. Çakılması } & 0,142 \\
\text { Cep Etiketi } & 0,065
\end{array}
$$

\subsubsection{AHP Skorları İle Oluşturulan Dağıtım Anahtarları}

İkili karşılaştırma matrislerinin çözümü sonucunda elde edilen faaliyet sürücülerine ilişkin dağıtım anahtarları Tablo 6'da gösterilmiştir. 


\begin{tabular}{lllll}
\multicolumn{5}{c}{ Tablo 6: Dağıtım Anahtarları } \\
\hline & Elektrik & $\begin{array}{l}\text { Tamir- } \\
\text { Bakım }\end{array}$ & Amortisman & Diğer Giderler \\
\hline Satın Almam & & & & 0,227 \\
Ebatlama & 0,203 & 0,207 & 0,101 & 0,370 \\
Ciltleme & 0,528 & 0,508 & 0,524 & 0,079 \\
Katlama & 0,054 & 0,051 & 0,071 & 0,117 \\
M. Çakılması & 0,103 & 0,077 & 0,148 & 0,142 \\
Cep Etiketi & 0,112 & 0,157 & 0,156 & 0,065 \\
\hline Toplam & 1,000 & 1,000 & 1,000 & 1,000 \\
\hline
\end{tabular}

\subsubsection{AHP Skorları İle Oluşturulan Dağıtım Tutarları(も)}

Endirekt giderler, AHP ağırlıklarını kullanmak suretiyle, faaliyetlere dağıtılmıştır. Dağıtıma ilişkin sonuçlar Tablo 7'de ki gibidir. Bu değerler, dağıtım anahtarları giderlerin tutarlarının çarpılması ile elde edilmiştir.

Tablo 7: Endirekt Giderlerin Faaliyetlere Yüklenmesi

\begin{tabular}{|c|c|c|c|c|c|c|c|c|}
\hline & $\begin{array}{l}\text { Satın } \\
\text { Alma }\end{array}$ & Ebatlama & Ciltleme & Katlama & $\begin{array}{l}\text { M. } \\
\text { Çakılması }\end{array}$ & $\begin{array}{l}\text { Cep } \\
\text { Etiketi }\end{array}$ & Toplam (も) & $\begin{array}{l}\text { Yüzde } \\
(\%)\end{array}$ \\
\hline Elektrik & - & $2.097,46$ & $5.455,46$ & 557,95 & $1.064,23$ & $1.157,22$ & 10.332 .32 & 30,0 \\
\hline Tamir-Bakım & - & 232,48 & 570,54 & 57,28 & 86,48 & 176,33 & $1.123,11$ & 3,3 \\
\hline Amortisman & - & $2.175,55$ & $\begin{array}{l}11.287,0 \\
1\end{array}$ & $1.529,35$ & $3.187,93$ & $3.360,26$ & $21.540,10$ & 62,7 \\
\hline Diğer Giderler & 307,16 & 500,65 & 106,89 & 158,31 & 192,14 & 87,95 & $1.353,10$ & 4,0 \\
\hline Toplam (も) & 307,16 & $5.006,14$ & $17.419,90$ & $2.302,89$ & $4.530,78$ & $4.781,76$ & $34.348,64$ & 100,0 \\
\hline Yüzde (\%) & 0,9 & 14,6 & 50,7 & 6,7 & 13,2 & 13,9 & 100,0 & \\
\hline
\end{tabular}

\subsection{Faaliyet Havuzlarında Toplanan Giderlerin Ürüne Yüklenmesi}

$\mathrm{Bu}$ aşamada yine uzmanların ikili karşılaştırmalarından faydalanmak suretiyle dar klasörlerin üretim faaliyet sürecinin \%21,4'ünü geniş klasörlerin ise \%78,6'sını kullandıkları belirtildi

Tablo 8: Havuzda Toplanan Giderlerin Ürünlere Yüklenmesi

\begin{tabular}{llll}
\hline & $\begin{array}{l}\text { Dar Klasör } \\
\mathbf{( 3 1 * 6 1 )}\end{array}$ & $\begin{array}{l}\text { Geniş Klasör } \\
\mathbf{( 3 1 * 6 4 )}\end{array}$ & Toplam \\
\hline Satın Alma & 65,73 & 241,43 & 307,16 \\
Ebatlama & $1.071,31$ & $3.934,83$ & $5.006,14$ \\
Ciltleme & $3.727,86$ & $13.692,04$ & $17.419,90$ \\
Katlama & 492,82 & $1.810,08$ & $2.302,90$ \\
Mekanizmanın Çakılması & 969,59 & $3.561,19$ & $4.530,78$ \\
Cep Etiketi & $1.023,30$ & $3.758,46$ & $4.781,76$ \\
\hline Toplam (TL) & $7.350,61$ & $26.998,03$ & $34.348,64$ \\
\hline Yüzde & $\% 21,4$ & $\% 78,6$ & $\% 100$ \\
\hline
\end{tabular}

Faaliyete dayalı maliyetle yöntemi ile hesaplanan endirekt gider ile direk giderlerin toplamı nihaiyi üretim maliyetini oluşturmaktadır. Toplam üretim maliyeti üretim miktarına bölünerek elde edilen birim maliyet Tablo 9'da yer almaktadır. 


\begin{tabular}{|c|c|c|c|c|c|c|}
\hline & \multirow{2}{*}{$\begin{array}{c}\text { Endirekt } \\
\text { Gider } \\
\text { FDM-AHP ile } \\
\text { Dağıtım }\end{array}$} & \multicolumn{2}{|c|}{ Direkt Gider } & \multirow[b]{2}{*}{ Endirekt+Direkt (も) } & \multirow[b]{2}{*}{$\begin{array}{l}\text { Üretim } \\
\text { (Adet) }\end{array}$} & \multirow[b]{2}{*}{$\begin{array}{l}\text { Birim } \\
\text { Maliyet }\end{array}$} \\
\hline & & D.İ & D.İ.MLZ & & & \\
\hline DK & $7.350,61$ & $14.512,93$ & $97.146,06$ & $119.009,60$ & 31.200 & 3,81 \\
\hline GK & $26.998,03$ & $53.304,50$ & $356.807,50$ & $437.110,02$ & 93.600 & 4,67 \\
\hline Toplam & $34.348,64$ & $67.817,43$ & $453.953,62$ & $556.119,62$ & & \\
\hline
\end{tabular}

Tablo 8 incelediğinde ürünler için birim maliyetin dar klasör (DK) içi 3,81も iken geniş klasör (GK) için ise 4,67もolduğu belirlenmiştir.

Geleneksel yönteme göre işletme birim maliyet hesaplamasını toplam üretim maliyetini üretilen ürün miktarına bölmek suretiyle hesaplamaktadır. İşletme hâlihazırda iki tür klasör üretimi gerçekleştiriyor olsa da birim maliyet hesaplamasını geleneksel yönteme göre yaparken sadece ebatlama bölümündeki farklılığ $\mathrm{DK}(31 * 61)$ ve GK $(31 * 64)$ dikkate alarak DİMM'deki mukavva farklılığını hesaplamada dikkate almaktadır. Geleneksel yöntemde endirekt giderlerin dağıtımı için üretim miktarlarını kullanmaktadır. Her bir ürüne üretildiği miktar oranında endirekt giderlerden pay düşmektedir. Son sütunda ise geleneksel yönteme göre birim maliyetler yer almaktadır.

Tablo 10: Geleneksel Yönteme Göre Birim Maliyet Hesaplama

\begin{tabular}{lllllll}
\hline & $\begin{array}{l}\text { Üretim } \\
\text { Miktarları } \\
\text { (Adet) }\end{array}$ & $\begin{array}{l}\text { Dağıtım } \\
\text { Anahtarı }\end{array}$ & $\begin{array}{l}\text { Endirekt } \\
\text { Giderler }\end{array}$ & $\begin{array}{l}\text { Direkt Gider } \\
\text { Toplamı }\end{array}$ & Toplam (も) & $\begin{array}{l}\text { Birim } \\
\text { Maliyet } \\
\text { (も/Adet) }\end{array}$ \\
\hline DK & 31.200 & 0,250 & $8.587,16$ & $125.442,75$ & $134.029,91$ & 4,30 \\
GK & 93.600 & 0,750 & $25.761,48$ & 396.328 .23 & $422.089,71$ & 4,51 \\
Toplam & 124.800 & & $34.348,64$ & $521.770,98$ & $556.119,62$ & \\
\hline
\end{tabular}

Tablo 10 incelediğinde geleneksel yöntemde ürünler için birim maliyetin dar klasör (DK) 4,30もve geniş klasör (GK) için 4,46も olduğu belirlenmiştir.

Sonuç

Teknolojinin hızlı değişimi ile birlikte üretim teknik ve yaklaşımları farklılaşmakta ve hızla gelişmektedir. Bu değişim süreci, beraberinde üretim süreçlerinde yeni olguların ortaya çıkmasına neden olduğu gözlemlenmektedir. Yeni üretim süreçlerinin ortaya çıkması, kaynakların daha etkin değerlendirilmesi ve kullanılması için ayrıca önem arz etmektedir.

Yönetim etkinliğinin sağlanabilmesi için maliyetlerin doğru hesaplanması gerekmektedir. Birden fazla ürün üreten işletmelerde, direkt işçilik gideri ve direkt ilk madde ve malzeme gideri mamul maliyetine doğrudan yükleniyor olsa da genel üretim giderlerinin mamullere dağıtımında önemli sorunlar meydana gelmektedir. Gerçeklesen endirek maliyetler (GÜM) direkt olarak mamullere yüklenemediği için dağıtım anahtarı problemi ile karsı karsıya kalınmaktadır. Maliyetlerin gerçekleştiği alanlarda ve hangi faaliyetlerle ilgili olduğu hangi faaliyetin gerçekleşmesinde ne kadar yararlanıldığının belirlenmesi ve buna göre doğru bir maliyet dağıtımının yapılabilmesi için FDM ve AHP entegre edilerek Sivas'ta faaliyette bulunan sanayi işletmesinde uygulaması yapılmış buna göre elde edilen sonuçlar işletmeler açısından stratejik bir karar unsuru olarak objektif bir şekil almıştır. FDM uygulaması için ihtiyaç duyulan dağıtım anahtarları yedi farklı uzmandan elde edilen AHP değerlendirmeleri yardımıyla belirlenmiştir.

Çalışma sonucunda; işletmenin geleneksel maliyet muhasebesi ile hesaplamış olduğu birim maliyet ile FDM-AHP tekniği yardımıyla hesaplanan birim maliyetlerin farklı olduğu tespit edilmiştir. FDMAHP tekniği ile birlikte, işletmenin hâlihazırda kullandığı birim maliyetlerden farklı olarak ürün 
modeli bazında birim maliyetlerin hesaplamasında faaliyet süreçleri ve kullandıkları faaliyet maliyetlerin farklılaştığı tespit edilmiştir. İşletmenin ürettiği iki tip model üründen geniş klasör( GK) modeli için \%3 oranında daha yüksek birim maliyet hesaplanırken dar klasör(DK) modeli için ise $\% 12$ oranında düşük birim maliyet hesaplaması gerçekleştirilmiştir. Bu durum, işletmenin satış hacmine bağlı olarak mali tablolarında önemli değişikliklere neden olabilecektir. Yanlış fiyatlandırma sonucunda işletmenin uzun vadede bir takım olumsuzluklarla da karşılaşması söz konusu olabilir. Bu nedenle yöneticilerin maliyet sistemlerini gözden geçirmeleri önerilmektedir. Ayrıca çalışmada hangi faaliyette daha çok gider tüketildiği tespit edilmiştir. Böylelikle yöneticiler hangi faaliyetin daha çok maliyet tükendiğin de tespit etmiş olacaktır. Zira çalışmada ciltleme faaliyeti giderlerin yarısını (bkz Tablo:10) tüketmektedir.

\section{Kaynakça}

Abdioğlu, H. (2012). Maliyet muhasebesi. Balıkesir: Dora Yayınları.

Arzova S. B. (2002). Faaliyet tabanl maliyet yönetimi. İstanbul: Türkmen Kitabevi.

Barnes, F. C. (1992), "Management's stake in improved decision making with activity based costing." S.A.M. Advanced Management Journal, 57(3): 20-26.

Büyükmirza, K. (2010). Maliyet ve yönetim muhasebesi: tek düzene uygun bir sistem yaklaşımı. Ankara: Gazi Kitabevi.

Büyükşalvarcı, A. (2006). "Faaliyet tabanlı maliyetleme ve bankalarda bir uygulama." Selçuk Üniversitesi Karaman İ.I.B.F. Dergisi, 10 (9): 160 - 180.

Cuma, F. ve Akpınar, S. ( 2019). "Sağl1k işletmelerinde faaliyet tabanlı maliyetleme yönteminin uygulanmasını etkileyen faktörlerin belirlenmesi." Hacettepe Sağllk İdaresi Dergisi, 22(1): $1-18$.

Garrison, N. (1994). Managerial accounting: conceptsfor planning control decisionmaking. 7th edition, Irwin, U.S.A.

Gümüş, Y. (2007). Üretim işletmelerinde lojistik maliyetlerinin faaliyet tabanl maliyetleme yöntemine göre hesaplanması ve bir uygulama. Yayınlanmamış doktora tezi, Dokuz Eylül Üniversitesi Sosyal Bilimler Enstitüsü, İzmir.

Kaplan, R.S. ve Cooper R. (1998). Cost \& Effect: using integrated cost systems todrive profitabilityand performance. Boston: Harvard Business School Pres.

Köse, T. (2005) "Faaliyete dayalı maliyetleme ve kısıtlar teorisinin bütünleştirilmesi.” Muhasebe ve Denetime Bakış Dergisi, 14: 127-148.

Köse, T. (2005) "Faaliyete Dayalı Maliyetleme ve Kısıtlar Teorisinin Bütünleştirilmesi." Muhasebe ve Denetime Bakış, 4(14), 127-148.

Lanen vd. (2011). Fundamentals of Cost Accounting, 3rd Edition, USA: Mcgraw-Hill.

Zimmerman, J. L. (2011). Accounting for decision making and control, SeventhEdition, U.S.A.: Mcgraw-HillIrwin.

Hardan, A. S. ve Shatnawi, T. M. (2013) ."Impact of applyingthe abc on improvingthe financial performance in telecomcompanies." International Journal of Business and Management, 8 (12): 48-61.

Taşçı, H. (2004). Aktiviteye dayalı maliyet sistemi ve Türkiye Cumhuriyeti Merkez Bankası uygulama örneği. TCMB Uzmanlık Yeterlilik Tezi, Ankara. 
Karataş, Ö. N., Bekçi, İ., Ömürbek, V. (2014), "Bulanık faaliyet tabanlı maliyetleme ve bir uygulama." Muhasebe Bilim Dünyası Dergisi, 16 (1): 63-93.

Babad, Y. ve Balachandran, B. (1993). "Cost driver optimization in activity-based costing." The Accounting Review, 3(68): 563-575.

Merchant, K. ve Shieeld, M. (1993). "Commentary on when and why to measure costless accuretly to improve decision making." Accounting Horizons, 7, 76-81.

Esmeray, M. ve Güngör Tanç, Ş. (2009). Çevresel maliyetlerin mamullere yüklenmesinde kullanılan dağıtım anahtarlarının seçiminde analitik hiyerarşi yöntemi ve bir uygulama. Süleyman Demirel Üniversitesi İktisadi ve İdari Bilimler Fakültesi Dergisi, 14(2), 241-260.

Shashikumar, G., Sarkar, B. ve Sanyal, S.K. (2017). "Evaluation of facilities layout alternatives by integ-rating concepts of ABC \& AHP." International Journal of Engineering Science Invention, 6(7): 20-25.

Saaty, T. L. ve Vargas, L. G. (2012). Models, Methods, Concepts\& Applications of the Analytic Hierarchy Process. New York: Springer Science+Business Media.

Baykasoğlu, A. ve Kaplanoğlu, V. (2008). Application of activity-basedcostingto a land transportationcompany: a case study. International Journal of ProductionEconomics, 116(2): 308324.

Can, A. V., Göksu, A., Faydalı, F. (2018). "Maliyet dağıtım anahtarlarının bütünleşik karar verme modeli ile seçimi." Muhasebe ve Vergi Uygulamaları Dergisi, 11 (3): 363-391.

Barfield, J., Raiborn, C.ve Kinney, M. (1994). Cost accounting: traditions and innovations. St. Paul: South western.

Dumanoğlu, S. (2005). "Faaliyet tabanlı maliyet sistemi: bir dijital baskı işletmesinde uygulama." Muhasebe Finansman Dergisi, Temmuz: 105-116.

Özçalıcı, M. ve Kaya, A. (2019). "Faaliyet tabanlı maliyetleme tekniğinde maliyet sürücülerinin analitik hiyerarşi prosesi ile belirlenmesi: bir uygulama." Işsletme Araştırmaları Dergisi, 11(4), 3035-3050.

Mowen, M. M. and Hansen, D. R. (2011). Introduction to cost accounting. (International edn). Spiceland: Cengage Learning Services. 